\title{
RELATO DE EXPERIÊNCIA: REFLEXÕES SOBRE O PAPEL DO PROFISSIONAL DE EDUCAÇÃO FÍSICA NO ÂMBITO DAS DEFICIÊNCIAS MULTIPLAS
}

\author{
RELATO DE EXPERIENCIA: REFLEXIONES SOBRE EL PAPEL DEL \\ PROFESIONAL DE EDUCACIÓN FÍSICA EN EL ÁMBITO DE LAS DEFICIENCIAS \\ MULTIPLES
}

EXPERIENCE REPORT: REFLECTIONS ON THE ROLE OF PHYSICAL EDUCATION PROFESSIONAL IN THE FIELD OF MULTIPLE DEFICIENCIES

\author{
Francisco Claudeci Faustino TEIXEIRA ${ }^{1}$ \\ Ana Paula Mendes SANTIAGO ${ }^{2}$ \\ Jacqueline de Oliveira LIMA ${ }^{3}$ \\ Stela Lopes SOARES ${ }^{4}$ \\ Heraldo Simões FERREIRA ${ }^{5}$
}

RESUMO: Este trabalho científico privilegiou relatar as práticas inclusivas da disciplina: Educação Física para Pessoas com Deficiência. As ações acolhedoras foram realizadas na Associação de Pais e Filhos Excepcionais - APAE. Sendo efetivadas essas vivências no campo de atuação pautado no interesse em compreender o papel do Profissional de Educação Física no âmbito das deficiências múltiplas. Este trabalho tem como objetivo descrever as atividades interativas com as pessoas portadoras de deficiências múltiplas na APAE por meio da disciplina Educação Física para as Pessoas com Deficiência. A metodologia utilizada pelo estudo foi a pesquisa-ação, tendo como propósito produzir informações e conhecimentos de uso aprofundado, inclusive ao nível pedagógico, que promove condições para ações e transformações de situações dentro da própria instituição de atendimento às pessoas excepcionais. Portanto discutiu-se o quanto qualquer profissional quer ser visto com um constituinte formativo deferenciado em seu campo de atuação, e com o Profissonal de Educação Física não é muito deferente, na maioria das vezes se tem a consciência da gama de beneficios que a profissão pode proporcionar nas diferentes práticas, mas que ainda encara desafios quanto a sua legitimidade concreta no progresso do indíviduo. Conclui-se que é imprescindível que o Profissional de Educação Física ocupe este espaço.

PALAVRAS-CHAVE: Profissional de educação física. Deficiências múltiplas. Ações inclusivas. Práticas interativas.

\footnotetext{
1 Universidade Estadual Vale Acaraú (UVA) - CE - Brasil. Graduando em Educação Física. E-mail: claudecyr10@gmail.com

2 Universidade Estadual Vale Acaraú (UVA) - CE - Brasil. Graduanda em Educação Física. Email: paulacarpes2@gmail.com

3 Universidade Estadual Vale Acaraú (UVA) - CE - Brasil. Graduanda em Educação Física. Email: eaakinha@gmail.com

4 Universidade Estadual do Ceara- UECE. Brasil. Mestranda em Ensino na Saúde. Email: stelalopesoares@hotmail.com

5 Universidade Estadual do Ceará - UECE. Brasil. Doutor em Saúde Coletiva. Professor Adjunto do Curso de Educação Física da Universidade Estadual do Ceará - UECE. Email: heraldo.simoes@uece.br
} 
RESUMEN: Trabajo científico privilegió relatar las prácticas inclusivas de la disciplina: Educación Física para Personas con discapacidad. Las acciones acogedora se realizaron en la Asociación de Padres e Hijos Excepcionales - APAE. Siendo efectivizadas esas vivencias en el campo de actuación pautado en el interés en comprender el papel del Profesional de Educación Física en el ámbito de las deficiencias múltiples. Este trabajo tiene como objetivo describir las actividades interactivas con las personas portadoras de deficiencias múltiples en la APAE através de la disciplina Educación Física para las Personas con discapacidad. La metodología utilizada por el estudio fue la investigación-acción, teniendo como propósito producir informaciones y conocimientos de uso profundizado, incluso al nivel pedagógico, que promueve condiciones para acciones y transformaciones de situaciones dentro de la propia institución de atención a las personas excepcionales. Por lo tanto se discutió cuánto cualquier profesional quiere ser visto con un constituyente formativo deferenciado en su campo de actuación, y con el Profissonal de Educación Física no es muy deferente, la mayoría de las veces se tiene la conciencia de la gama de beneficios que la profesión puede En las prácticas diferentes, pero que todavía encara desafíos en cuanto a su legitimidad concreta en el progreso del individuo. Se concluye que es imprescindible que el Profesional de Educación Física ocupe este espacio.

PALABRAS-CLAVE: Profesional de educación física. Deficiencias múltiples. Acciones inclusivas. Prácticas interactivas.

ABSTRACT: This scientific work privileged to report the inclusive practices of the discipline: Physical Education for People with Disabilities. The welcoming actions were carried out in the Association of Parents and Exceptional Children - APAE. These experiences are effective in the field of action based on the interest in understanding the role of the Physical Education Professional within the scope of multiple deficiencies. This paper aims to describe the interactive activities with people with multiple disabilities in APAE through the discipline Physical Education for People with Disabilities. The methodology used by the study was to action research, with the purpose of producing information and knowledge of in-depth use, including at the pedagogical level, which promotes conditions for actions and transformations of situations within the institution itself to care for exceptional people. Therefore, it was discussed how much any professional wants to be seen with a formative constituent deferenced in their field of activity, and with the Professional of Physical Education is not very deferent, most of the times one is aware of the range of benefits that the profession can To provide in the different practices, but which still raises doubts as to its concrete legitimacy in the progress of the individual. It is concluded that it is imperative that the Physical Education Professional occupy this space.

KEYWORDS: Physical education professional. Multiple disabilities. Inclusive actions. Interactive practices.

\section{Introdução}

Este trabalho trata-se de um Relato de Experiência elaborado a partir das ações inclusivas com as deficiências múltiplas na Associação de Pais e Filhos Excepcionais-APAE, sobre a organização e desenvolvimento da disciplina: Educação Física para Pessoas com 
deficiência do Curso de Licenciatura em Educação Física na modalidade presencial da Universidade Estadual Vale do Acaraú-UVA, Sobral-CE.

O Estagio Supervisionado é a etapa no processo de formação do acadêmico em que ele coloca em prática todos os conhecimentos adquiridos em sua graduação no campo de atuação, buscando assim, o aperfeiçoamento almejado para o exercício da profissão (AZOLINI, 2012).

Nesta perspectiva, o acadêmico estuda os conteúdos relacionados aos métodos, técnicas e estratégias de práticas inclusivas e interativas com pessoas portadoras de deficiências múltiplas, ao compreender os procedimentos teóricos o discente em formação vai até seu futuro âmbito de exercício docente para aplicar os conhecimentos assimilados na prática, concretizando assim, a práxis pedagógica.

A aproximação entre a comunidade Acadêmica e a APAE aconteceu no dia 27 de junho de 2016. Primeiramente por meio de uma reunião exclusiva entre a diretora da APAE e o Acadêmico. Neste princípio foi negociada a efetivação das atividades acolhedoras propostas pela a disciplina Educação Física para Pessoas com Deficiência. Ficaram autorizadas as visitas e que seriam feitas observações no âmbito das pessoas com deficiências múltiplas.

A deficiência múltipla é a ocorrência de duas ou mais deficiências simultaneamente, sejam intelectuais, físicas, distúrbios neurológicos, emocionais, linguagem e desenvolvimento educacional, vocacional, social e emocional, dificultando sua autossuficiência. Caracterizamse por atrasar o desenvolvimento global da criança, dificultando sua aprendizagem e autonomia, diante desse quadro, o indivíduo pode já nascer ou adquirir baixa visão e deficiência física ou intelectual, cegueira e distúrbios neurológicos, surdez e mobilidade física, entre outros, de níveis que vão de leve a severo (MEC, 2006).

Dados fornecidos pelo censo demográfico, realizado em 2000, pelo Instituto Brasileiro de Geografia e Estatística (IBGE), indicam a existência de 24 milhões de pessoas deficientes cadastradas, sejam portadores de deficiências mentais, físicas, auditivas, visuais ou de deficiências múltiplas. Em pesquisas da Organização Mundial de Saúde (OMS), observa-se que $10 \%$ da população mundial tem algum tipo de deficiência.

Em momento de acordos e comunicação entre os membros envolvidos foi assinado o oficio pela responsável da instituição. Diante das propostas interativas apresentadas à diretora, ela avisou que eles estavam no final do semestre e que com isso também estavam finalizando as atividades, talvez não fosse possível realizar todas as ações como se pretendia, mas ela firmou minha a ida até a APAE no dia seguinte para iniciar as atividades integrativas propostas pela a disciplina, e que eu s adequasse com as atividades restantes.

No dia 28 de junho de 2016 cheguei à APAE às 7 horas da manhã e esperei a chegada 
do Profissional de Educação Física da Instituição. Quando ele chegou, me identifiquei como acadêmico do curso de Educação Física da Universidade Estadual Vale do Acaraú-UVA, Sobral-CE.

Depois que me identifiquei, perguntei ao docente sobre quais eram as atividades que seriam realizadas naquele dia, ele me falou que seriam o ensaio da quadrilha junina para o chitão e aula de natação, mas de repente ele recebeu um comunicado da coordenação cancelando as atividades citadas anteriormente.

Diante do cancelamento das atividades o Profissional de Educação Física me mostrou todos os espaços da instituição, em cada espaço ele me apresentava aos demais profissionais da equipe multidisciplinar daquela instituição como acadêmicos do Curso de Educação Física da UVA, fui bem recepcionado por onde passei. Ficou combinado para o dia seguinte que eu fosse observar o chitão da APAE, onde todos os deficientes e familiares iriam estar presentes.

No dia 29 de junho de 2016 cheguei à APAE 8 horas da manhã e me dirigi para a quadra poliesportiva onde iria acontecer a chitão desta instituição, iniciou-se a festa junina por volta de $08 \mathrm{~h} 30 \mathrm{~min}$ e terminou às 11 horas.

Nesse evento tive a oportunidade de observar como os deficientes se comportavam e interagiam dentro daquele espaço e com as demais pessoas presentes no evento.

Este artigo objetiva descrever as atividades interativas com as pessoas portadoras de deficiências múltiplas na APAE dentro das ações ementarias da disciplina de Educação Física para Pessoas com Deficiência. E abrir discussões sobre os processos de observação, coparticipação e docência supervisionada, que atualmente é essencial em todos os âmbitos do processo de formação dos futuros profissionais.

\section{Método}

Este estudo caracteriza-se como uma pesquisa-ação, que tem como propósito produzir informações e conhecimentos de uso mais efetivo, inclusive ao nível pedagógico, que promove condições para ações e transformações de situações dentro da própria instituição de atendimento as pessoas excepcionais.

Tripp (2005) diz que a pesquisa-ação no espaço educacional é um método essencial para o aperfeiçoamento de docentes e de pesquisadores de forma que sejam capazes de utilizar os resultados encontrados nas ações como ferramenta para melhorar a qualidade do ensino, ou seja, todos os achados têm que ser destinados de volta para os próprios educandos estudados nas pesquisas científicas. 


\section{Amostra}

Este estudo foi realizado na Associação de Pais e Filhos Excepcionais - APAE dentro das propostas emetarias da disciplina: Educação Física para Pessoas com Deficiência do Curso de Licenciatura em Educação Física da Universidade Estadual Vale da Acaraú-UVA, Sobral-Ce. A APAE fica Localizada na Rua Maestro Acácio Alcantara, 231, Junco, Sobral, Ceará. Esta Instituição atende pessoas com necessidades especiais, com faixa etária de 0 a 42 anos de idade, sendo de ambos os sexos e com as mais diversificadas deficiências. Durante a efetivação deste escopo foram garantidos todos os principios éticos e morais dos membros envolvidos no estudo.

O Conselho Nacional de Saúde (2012) afirma que é primordial respeitar a dignidade humanas, é essencialmente louvavel preservação dos integrantes engajados nas pesquisas cientificas envolvendo seres humanos.

\section{Instrumentos}

Nesse estudo se utilizou a observação participante com instrumento efetivo na realização deste escopo. As observações aconteceram durante o período de funcionamento da APAE por meio de visitas a cada espaço da instituição. Primeiramente foram realizadas visitas para o reconhecimento do espaço, e seguida, foram identificados os espaços em que seriam realizadas as observações e posteriormente concretizadas.

Gil (2008) afirma que a observação participante tem como meta explicar um elemento, primando o estado natural daquele elemento, retratando minuciosamente com ele realmente acontece, procurando compreender essencialmente os meios subjacentes aos dados observados. Portanto, trata-se de uma pesquisa qualitativa, na qual se faz mais inferência sobre o fenômeno estudado.

Peruzzo (2003) ressalta a necessidade da presença do acadêmico observador de forma efetiva no espaço a ser investigado, onde este pode identificar as dificuldades existentes em seu campo de atuação. O observador pode ainda partilhar de modo permanente e contextualizado das atividades do grupo e situação do grupo estudado. Ou seja, ele se engaja nas ações, além de dividir os achados científicos.

\section{Procedimentos}

A ementa da disciplina Educação Física para Pessoas com deficiência, contém como 
atividade de encerramento, a realização de visitas dos acadêmicos as instituições de ensino que atendem pessoas com necessidades especiais, sejam elas especializadas ou não. Onde os acadêmicos escolhem uma determinada entidade para a realização das vivências no âmbito inclusivo das deficiências Múltiplas e, ao concluírem, tem que apresentar na sala de aula a realidade defrontada no campo de atuação.

A autorização para a realização das atividades aconteceu por de um oficio expedido pela a professora responsável pela disciplina, este foi apresentado para a diretora da APAE, em que ela concordou a efetivação das atividades que se pretendia naquela instituição.

As visitas aconteceram no turno da manhã, onde primeiramente se conheceu os espaços físicos da APAE, como estava organizado funcionamento, se identificou o espaço de atuação do Profissional de Educação Física e posteriormente à realização das observações no âmbito das deficiências múltiplas.

Utilizou-se como estratégia a observação inicial diagnóstica, que ocorreram nos dias 28 e 29 de junho de 2016 no horário das 07 horas às 11 horas da manhã, com o objetivo de identificar as atividades e ações acolhedoras desenvolvidas pelo o Profissional de Educação Física na APAE.

Na primeira visita foi solicitada para o Profissional de Educação Física que mostrasse o seu espaço mais utilizado, assim foi feito. Em seguida, conhecemos os demais membros da equipe multidisciplinar da instituição, que se unem para garantir o melhor tratamento dos membros envolvidos na ação.

$\mathrm{Na}$ segunda visita observamos o chitão da APAE, nele observamos como todos os deficientes se relacionam durante a quadrilha junina e nas demais atividades do festejo.

Os elementos planejados durante o chitão foram bem recebidos por todos os deficientes, participaram de forma bem efetivas dos momentos juninos.

\section{Análise estatística}

Os resultados foram registrados em forma de relatório no qual se encontram descritos o processo das observações, assim como uma descrição sucinta e contextualizada sobre a relevância da realização das atividades ementarias da disciplina Educação Física para Pessoas com Deficiência na APAE.

\section{Resultados}


Diante da vivência na Associação de Pais e Filhos Excepcionais-APAE, me deparei com o relato do Profissional de Educação Física da instituição, falando sobre a sua vontade de fazer com que a profissão seja mais reconhecida como uma área do conhecimento, que participa de forma mais efetiva na formação integradora das pessoas portadoras de necessidades especiais naquela renomada instituição de ensino inclusivo. Ressalta que:

Tenho muita vontade de realizar mais ações que amplie as contribuições da Educação Física neste espaço, mas me deparo com muitos desafios: a Educação Física aqui é mais vista como recreação, ela não é só essa concepção, é muito mais do que isso, os alunos tem muitas dificuldades em seu aspecto motor, com uma oportunidade maior para corrigir isso por meio dos conteúdos da Educação Física pode-se entender mais as contribuições desta profissão. Outro desafio é questão do número elevado de alunos deficientes durante as aulas, porque trabalhar com crianças já é complicado até com as consideradas normais, imagine com crianças portadoras de limitações. Com esses desafios da profissão fiz uma solicitação para a coordenação que colocasse um profissional para me auxiliar nas atividades, mas não fui atendido. O próximo para tentar convencê-los vai ser por maio de projeto que vou elaborar mostrando o quanto posso expandir o papel da Educação Física neste espaço.

Aqui se observou o quanto este profissional preza pelo o reconhecimento de sua área do conhecimento. Mesmo diante dos desafios, ele está sempre buscando alternativas para mostrar o quanto a profissão pode contribuir no processo de formação dos excepcionais, ou seja, tem-se a vontade de igualar os papeis dentro da equipe multidisciplinar.

Observou-se durante o chitão a felicidade de todos os excepcionais. Eles participavam das danças juninas de uma forma espetacular, mesmo existindo as limitações deles, sempre estavam demostrando o quanto aquele momento, para eles, era único.

Os cadeirantes durantes a quadrilha eram deslocados pelos profissionais da APAE com movimentos curvilíneos no centro do círculo dançante. A equipe multidisciplinar da instituição toda engajada no chitão, animando e incentivando todos os excepcionais a participarem dos momentos planejados exclusivamente para eles.

\section{Discussão}

Qualquer profissional quer ser visto com um constituinte formativo diferenciado em seu campo de atuação, e com o Profissonal de Educação Física não é muito deferente, na maioria das vezes se tem a consciência da gama de beneficios que a profissão pode proporcionar para as pessoas portadoras de necessidade educativas especias, mas infelizmente ainda encara dessafios quanto a sua legitimidade concreta no progresso do indíviduo. 
Em nosso cotidiano ainda existem paradgmas que limitam o papel efetivo e formador da Educação Física para as pessoas portadoras de necessidades educativas especias. Em nossa formação vemos novos métodos e técnicas dessa profissão que só intesificam a sua importancia, mas infelizmente existe também uma dificuldade por parte de alguns profissionais em convercer as demais profissões e pessoas sobre o quanto podemos contribuir com nossa atuação.

Os Parâmetros Curriculares Nacionais - Educação Física, apresentam orientações para o atendimento do princípio de inclusão, que estão direcionadas para garantir condições de participação, por meio de adaptações a serem realizadas pelo docente. O texto ressalta o valor do cultivo de atitudes de dignidade, de respeito próprio, de respeito às diferenças e de respeito às limitações da pessoa com deficiência. (BRASIL, SEF, 1998; PCN/SEF, 2000).

A indiferença é um desafio que deve ser superado no âmbito social de modo geral, por isso precisamos expandir as oportunidades inclusivas e interativas, para que todos possam desfrutar de novos conhecimentos e novas experiências e também, diferentes fatores devem ser reconsiderados para analisar o processo de inclusão nas escolas. (PRADO; VINHAS, 2013).

Neste contexto possuem muitas reflexões sobre a importância da inclusão e integração do aluno com os portadores de necessidades educativas especiais, no âmbito da escola regular e nas aulas de Educação Física.

Sabe-se que o educar não é algo que se consegue com facilidade e a inclusão se torna mais difícil ainda, pois vários elementos influenciam para esta dificuldade. O sistema educacional muitas vezes não proporciona subsídios necessários, como: políticas públicas para que seja facilitado o acesso dessas pessoas com necessidades educacionais especiais nas escolas brasileiras. Outras vezes as políticas até existem, mas de forma branda e no momento de colocá-las em prática não funcionam em sua totalidade ou como deveria de acordo com as teorias. (NETO; BUCIOLI, 2015).

Percebendo estes paradigmas (inclusão e interação), a pessoa com necessidades educativas especiais tem que ser vista e aceita pelas suas possibilidades e não pelas suas incapacidades. Depois da família, o âmbito educacional é o espaço primordial para o processo de socialização da criança. No caso específico da Educação Física é necessária que os profissionais envolvidos com a Educação Física adaptada produzam conhecimentos que tragam contribuições para modificar o contexto social em que vivem as pessoas com deficiência (MARQUES; SILVA; SILVA, 2008). 
Ainda na perspectiva da inclusão e interação que almeja combater conceitos estereotipados, contribuindo para o equilíbrio do processo de desenvolvimento das pessoas com necessidades educativas especiais, pois somente com mecanismos de compensação das limitações apresentadas por esses indivíduos, a escola poderá fortalecer atitudes de superação dos sentimentos de inferioridade. Essas ações devem ser implementadas com métodos e procedimentos especiais, que tornam possível a operacionalização de tais mecanismos. (NETO; BUCIOLI, 2015).

As pessoas excepcionais devem frequentar a Escola, não apenas para serem formados com cidadãos, mas para aprenderem se expressar movimentar, vivenciar e a serem estimulados como seres capazes de realizares as atividades dentro das suas limitações (MONTEIRO; SILVA, 2012).

Tem-se a necessidade de uma reflexão, ainda mais intensiva, no que diz respeito a conceitos e tratamentos para com as pessoas portadoras de necessidades especiais que atualmente causam confusão entre os educadores, principalmente entre aqueles que vivenciam o cotidiano escolar, sem possibilidade de atualização diante desta temática (NETO; BUCIOLI, 2015).

Os conhecimentos a cerca da inclusão social bem como os direitos firmados em lei, não devem ser apenas teorias, mas sim posto em prática. Pois assim, estaremos nos adaptando e fazendo a verdadeira inclusão desses indivíduos na sociedade, proporcionando alegria, diversão, saúde e qualidade de vida para essas pessoas e sempre seguindo o ritmo da atividade física (PRADO; VINHAS, 2013).

A Educação Física vem tentando resgatar uma educação voltada todas as diversidades existentes na sociedade, principalmente no que se refere aos alunos que apresentam necessidades especiais permanentes ou não. Proporcionado ao educando, com portador de necessidades educativas especiais de conhecer seu potencial e vencer seus limites, facilitando assim, a sua integração sempre que possível nas aulas de Educação Física, promovendo a interação entre todos os alunos.

O Docente de Educação Física disponibiliza de técnicas e ferramentas para que o processo ocorra de forma adequada e, acima de tudo, respeitando as dificuldades e o tempo de desenvolvimento de cada indivíduo. (CUNHA et al, 2009).

\section{Considerações finais}

Durante as vivências realizadas na APAE dentro das ações ementarias da Disciplina 
Educação Física para Pessoas com Deficiência, eu como futuro Profissional de Educação Física pude, com essa atuação em campo, compreender e ampliar o quanto podemos ofertar de conhecimento para os alunos excepcionais, sem menosprezar ou até mesmo sem tomar o espaço dos outros profissionais da equipe multidisciplinar.

Portanto, é imprescindível que o Profissional de Educação Física possa se munir dos mais diversificados recursos do conhecimento durante sua formação acadêmica, para quando estiver atuando na área saiba convencer as pessoas da importância daqueles conteúdos estarem inseridos naquele espaço.

As pessoas portadoras de necessidades especiais também podem viver em nossa sociedade como qualquer outro cidadão comum, para isso é necessário a conscientização da comunidade de modo geral, para a quebra do paradigma destinado aos excepcionais, que enfrentam dificuldades das deficiências e sociais por alguns indivíduos que não aceitam os excepcionais.

A inclusão só será completa quando houver uma conscientização maior, com a ajuda da politica que deve garantir matérias e recursos aos alunos, fazendo que todas as pessoas envolvidas tenham consciência para edificar saberes a partir das limitações dos alunos, como habilidades e competências.

É importante que haja uma ampla variedade de atividades sendo oferecida aos alunos para que se efetive a inclusão, principalmente no que se refere à educação Física Escolar, pois só será possível a inclusão de todos os alunos, a partir da criação diversificada de conteúdos e atividades.

\section{REFERÊNCIAS}

AZOLINI. L. C. O Estágio Supervisionado na Formação do Professor de Educação Física: um Estudo Autorreferente de um Estudante da ESEF da UFRGS no Ano de 2012 (Trabalho de Conclusão de Curso), p. 1-51. Repositório Digital da Universidade Federal do Rio Grande do Sul, Universidade Federal do Rio Grande do Sul, Rio Grande do Sul. Disponível em: < https://www.lume.ufrgs.br/bitstream/handle/10183/70296/000875908.pdf?sequence=1 >. Acesso em: 24 fev. 2016.

BRASIL. Educação Infantil: Saberes e Praticas da Inclusão. Brasília: MEC/SEF, 2006. Disponível em: <http://portal.mec.gov.br>. Acessado em: 24 mar. 2016.

BRASIL. Ministério da Educação. Parâmetros Curriculares Nacionais: Educação Física. Brasília, 1998. 
Conselho Nacional de Saúde. Resolução N 466, DE 12 de Dezembro de 2012. Disponível em: 〈http://conselho.saude.gov.br/resolucoes/2012/Reso466.pdf>. Acessado em: 02 de abr. 2016.

CUNHA, A. S.; CORTEZ, M.; LÔ, E. N.; PIONER, R.; FREITAS, B.; GOERL, D. B.. Relevância da Educação Física na Escola Inclusiva para o Individuo com Síndrome de Down. X Salão de Iniciação Científica - PUCRS, 2009. Disponível em: $<$ http://www.pucrs.br/edipucrs/XSalaoIC/Ciencias_da_Saude/Educacao_Fisica/71054AMANDA_SOUZA_CUNHA.pdf>.Acessado em: 04 de abr. 2016.

CHICON, F. J Inclusão e exclusão no contexto da educação física escolar. Revista movimento. v.14, n.01, p.13-38, Porto Alegre, 2008.

DAMAZIO, M. S.; BRUZI, A. T. Educação Física inclusiva e o papel da educação física no contexto escolar. Revista Ramal de Idéias, UFAC n. 1, 2008

GIL, A. C. Como elaborar projetos de pesquisa. Atlas, 4. ed. São Paulo, 2008.

MARQUES, K. G.; SILVA. R. V.; SILVA. R. F. Atividades Inclusivas na Educação Física Escolar. EFDesportes.com, Revista Digital, Buenos Aires, ano 13, n. 119, abril de 2008. Disponível em: <http://www.efdeportes.com/efd119/atividades-inclusivas-na-educacao-fisicaescolar.htm>. Acesso em: 06 abr. 2016.

MONTEIRO, J. A.; SILVA. M. S. A importância da atividade física para os deficientes físicos. EFDesportes.com. Revista Digital, Buenos Aires, ano, $15-\mathrm{N}^{\circ} 148$, setembro de 2010 .

NETO, A. O. BUCIOLI, S. A. A inclusão de alunos com necessidades educacionais especiais nas aulas de Educação Física escolar: um estudo de revisão bibliográfica. EFDesportes.com, Revista Digital, Buenos Aires, ano, 20 - $\mathrm{N}^{\circ}$ 207, agosto de2015. Disponível em: $<$ http://www.efdeportes.com/efd207/a-inclusao-nas-aulas-de-educacao-fisica.htm>. Acessado em: 06 de abr. 2016.

PERUZZO, C. M. K. Da observação participante à pesquisa-ação em comunicação: pressupostos epistemológicos e metodológicos. Anais... XXVI Congresso Brasileiro de Ciências da Comunicação - BH/MG - 2 a 6 Set 2003. Disponível em: < http://www.intercom.org.br/papers/nacionais/2003/www/pdf/2003_COLOQUIO_peruzzo.pdf >. Acesso em: 06 abr. 2016.

PRADO, J. S.; VINHAS, T. S. A Ginástica na escola como forma de inclusão de pessoas com deficiência física. (Trabalho de Conclusão de Curso), p. 1-29. Biblioteca Univap, Universidade do Vale do Paraíba, Faculdade de Educação e Artes, Jacareí-SP. Disponível em: <http://biblioteca.univap.br/dados/000004/000004c7.pdf>. Acess em: 06 abr. 2016.

TRIPP, D. Pesquisa-ação: uma introdução metodológica. Educação e pesquisa, v. 31, n. 3, 2005. 


\section{Como referenciar este artigo}

TEIXEIRA, Francisco Claudeci Faustino et al. Relato de experiência: reflexões sobre o papel do profissional de educação física no âmbito das deficiências múltiplas. Revista on line de Política e Gestão Educacional, Araraquara, v. 22, n. 1, p. 453-464, jan./abr., 2018. EISSN:1519-9029. DOI: 10.22633/rpge.v22.n.1.2018.10204

Submetido em: 31/07/2018

Aprovado em: 29/01/18 